\title{
The Effect of Global Warming and Ocean Acidification on Halichondira panicea Bacteria
}

\author{
George Hasnah \\ Bishop Montgomery High School, 5430 Torrance Blvd, Torrance, California, 90503,USA; hasnahgeorge@gmail.com
}

ABSTRACT: Marine Sponges are becoming an increasing source of novel biomedical and antibacterial compounds. Many of
these compounds are synthesized as secondary metabolites from symbiotic bacteria and have immense potential in the pharma-
ceutical industry. However, climate change may pose a threat to the viability of marine sponges and result in the loss of future
medical discoveries. Therefore, this paper looks at the effect climate change may have on marine sponges by subjecting fragments
of the marine sponge, Halichondria panicea, into aquaria representing different climate change scenarios to study the effect that
global warming and ocean acidification may have on its symbiotic bacteria. To model climate change towards the end of the $21^{\text {st }}$
century, conditions from the IPCC's 2014 climate change report were simulated to determine specific growth conditions. The
fragments were placed in the different RCP growth conditions for two weeks, then dissociated, filtered, and the extracts incubated
on Hektoen enteric agar for 48 hours. The results showed that climate change has adverse effects on the marine sponge, Halichon-
dria panicea, by decreasing their symbiotic bacterial population by around $18 \%$.
KEYWORDS: Earth and Environmental Sciences; Environmental Effects on Ecosystems; Marine Biology; Climate Change;
Marine Sponges.

\section{- Introduction}

Some forms of climate change have been modeled and discussed by the IPCC (Intergovernmental Panel on Climate Change). In doing so, they have created future scenarios (RCPs) detailing the rate of global warming and ocean acidification. These scenarios are based on the possible actions of humanity and how their intervention can change the course of climate change. ${ }^{1}$ An RCP number of 2.6 (RPC2.6) means increased human intervention and lowered ocean temperatures and stabilized $\mathrm{pH}$ levels. As the number increases $(6.0,8.5)$, so does ocean acidification and global warming, meaning that humans are taking little part in efforts to reduce carbon emissions and ocean acidification. These models show that the greater the projected changes are, the more stable and hospitable the environment will become. ${ }^{2}$ These RCP scenarios and their modeled effects are shown in Figure 1.

In a single liter of ocean water, there are over 1 billion individual bacterial cells and 10 billion viruses. Sponges, often referred to as the filters of the ocean, process over 50,000 times their volume of this pathogenic seawater in a day. ${ }^{3}$ As they are in continual contact with this endless stream of unique microorganisms, sponges begin to develop complex antibacterial compounds. Sponges attain these medical compounds through their symbiotic relationship with certain bacteria. Many times, when these bacteria are stressed, they produce a substance often referred to as a secondary metabolite. The molecules are highly specialized and are created to target specific problems. ${ }^{4}$ In the case of the marine sponge, Halichondria panicea, current research has shown that there are a variety of symbiotic bacteria living within the organism. However, the sponge's main symbiotic bacteria belong to the genus Rhodobacter (Proteobacteria, subdivision a). ${ }^{5}$ These bacteria are gram-negative and possess immense potentials in the pharmaceutical industry as they are able to synthesize highly complex antibiotics and other drugs. ${ }^{6}$ Since these bacteria are relatively small, $0.6-0.8$ microns long, a 1-micron syringe filters were used to purify sponge extracts. ${ }^{7}$
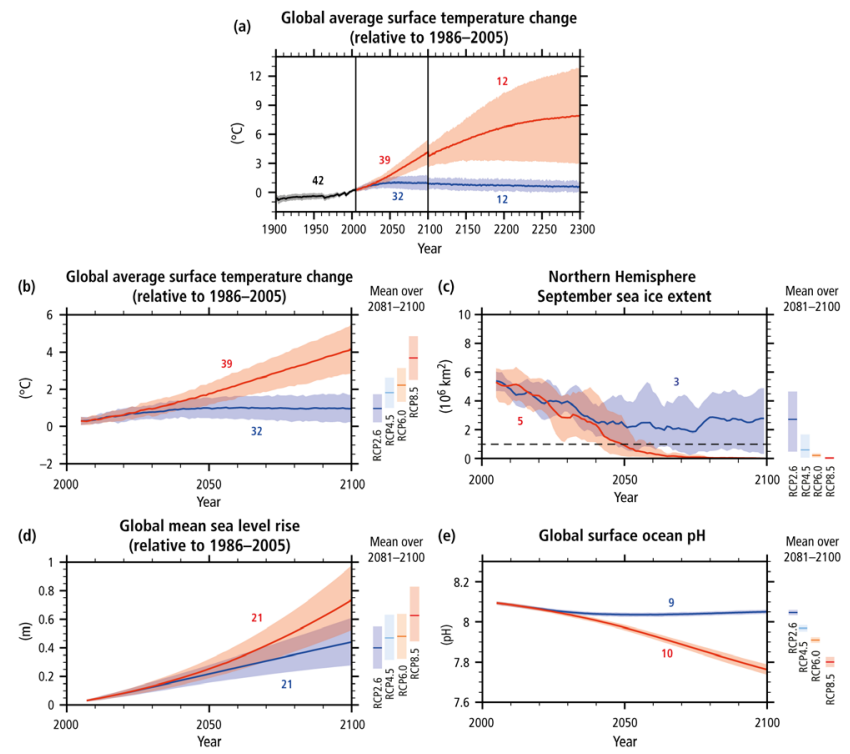

Figure 1: Projected effects of increases in atmospheric $\mathrm{CO}_{2}$ concentration by RCP senecio $2.6,4.5,6.0$, and 8.5 plotted as: a) surface temperature change, b) glacier melting, c) sea level rise, and d) ocean $\mathrm{pH}$ decline. Each RCP scenario, represented by the different colored projections, will have varying effects on the Earth's environment, however the most severe of which will increase global temperatures by about $4^{\circ} \mathrm{C}$ and decrease ocean $\mathrm{pH}$ levels by about 0.3 units by $2100 .^{2}$

Although some researchers have shown that sponges may transcend climate change, little is known about its bacteria, leaving much to be imagined for a sponge's medical potential 
in future scenarios. ${ }^{8}$ Therefore, the understanding of climate change as it relates to bacteria, is the first step towards understanding what possible challenges may lie in the future as it relates to the viability of marine sponges and the pharmaceutical industry. ${ }^{9}$

\section{Methods}

The Halichondria panicea sponges were raised in 2-gallon aquaria for the duration of two weeks and then subjected to different temperature and $\mathrm{pH}$ levels representing present and possible future conditions. After two weeks, the bacteria living in the sponges were sampled using standard techniques and were tested for viability. About 20 grams (wet weight) of Halichondria panicea sponge was collected from boat docks near the Cabrillo Marine Aquarium. They were then cut into 16 pieces, each measuring about one cubic centimeter, and placed into 16 different tanks (batch system). The tanks were separated into groups of 4 labeled trial 1 , trial 2 , trial 3 , and trial 4. Each tank within each trial was then labeled control, RCP 2.6, RCP 6.0, and RCP 8.5 and subjected to different water temperatures and $\mathrm{pH}$ levels based on their specific conditions shown in Table 1. The temperature in each of the test tanks were increased utilizing an aquarium heater and the $\mathrm{pH}$ decreased utilizing a soda streamer. To reduce the $\mathrm{pH}$ levels, $\mathrm{CO}_{2}$ was bubbled into artificial seawater and then the $\mathrm{pH}$ levels were manually adjusted by changing the proportion of unaltered seawater to $\mathrm{CO}_{2}$ streamed seawater. After 2 weeks, the sponges were washed with sterile artificial seawater, and the tissue was homogenized using a pestle and mortar. The extracts were then filtered through a 1 micron syringe filter, diluted to $10: 2$ concentration with artificial sea water and inoculated onto Hektoen enteric agar plates for 48 hours with a $100 \mu \mathrm{L}$ micropipette. After the incubation, the number of colonies on each plate were counted three times to derive a mean (to ensure consistency). Each tank had LED lighting strung above, cycling at 12 -hour intervals. Each tank also had a heater used to alter temperatures, a Fluval AquaClear Power Filter with activated charcoal and sponge filtration media, and a five-watt Hydor Koralia Circulation pump. The sponges were spot-fed once a day with $5 \mathrm{~mL}$ of Brightwell Aquatic's PhytoGreen-M phytoplankton suspension. A $10 \%$ water change was also conducted on the tanks every three days for the duration of the two-week testing period.

Table 1: Treatment group for each RCP scenario depicts temperature increase and $\mathrm{pH}$ decrease per $\mathrm{RCP}$ treatment group.

\begin{tabular}{|l|c|c|c|c|}
\hline \multicolumn{5}{|c|}{ Treatment Groups Water Conditions } \\
\hline & Control & $\mathbf{2 . 6}$ & $\mathbf{6 . 0}$ & $\mathbf{8 . 5}$ \\
\hline $\begin{array}{c}\text { Temperature } \\
\text { Increase (C): }\end{array}$ & 0 & 1 & 2.5 & 4 \\
\hline pH Decrease: & 0 & 0.07 & 0.2 & 0.3 \\
\hline
\end{tabular}

\section{Results and Discussion}

The number of viable bacterial colonies from each plate are given in Table 2. A One-way ANOVA test was performed on the raw data utilizing Excel Spreadsheets and yielded a P-value of 0.0223 (depicted in Figure 2). After the initial significance value was determined, a Tukey Post-hoc test was performed to determine which of the treatments were significantly different. It showed that there was statistical significance between the control and RCP 8.5 and RCP 6.0 treatments (depicted in Figure 3).

Table 1: Results showing the number of viable bacteria colonies from each treatment group.

\begin{tabular}{|c|c|c|c|c|}
\hline \multicolumn{5}{|c|}{ Number of Viable Bacteria Colonies Per Trial } \\
\hline & Control & $\mathbf{2 . 6}$ & $\mathbf{6 . 0}$ & $\mathbf{8 . 5}$ \\
\hline Trial 1 & 77 & 77 & 60 & 55 \\
\hline Trial 2 & 92 & 79 & 68 & 70 \\
\hline Trial 3 & 83 & 70 & 67 & 63 \\
\hline Trial 4 & 74 & 69 & 72 & 74 \\
\hline
\end{tabular}

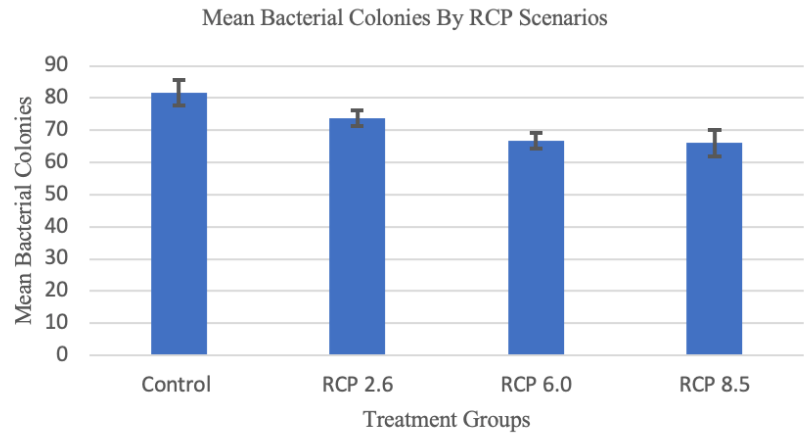

Figure 2: Graphed results from the one-way ANOVA statical test shows the average number of viable bacteria colonies found on agar dishes after each treatment. There is a general decreasing trend in the number of viable colonies as RCP scenarios worsen; the treatment groups are also proven to be statically different by the resulted P-value of 0.0223 .

\begin{tabular}{l|r|l|l}
$\begin{array}{l}\text { treatments } \\
\text { pair }\end{array}$ & $\begin{array}{l}\text { Tukey HSD } \\
\text { Q statistic }\end{array}$ & $\begin{array}{l}\text { Tukey HSD } \\
\mathrm{p} \text {-value }\end{array}$ & $\begin{array}{l}\text { Tukey HSD } \\
\text { inferfence }\end{array}$ \\
\hline A vs B & 2.3095 & 0.3989372 & insignificant \\
\hline A vs C & 4.3956 & 0.0392897 & $* \mathrm{p}<0.05$ \\
\hline A vs D & 4.6191 & 0.0298164 & $* \mathrm{p}<0.05$ \\
\hline B vs C & 2.0860 & 0.4814655 & insignificant \\
\hline B vs D & 2.3095 & 0.3989372 & insignificant \\
\hline C vs D & 0.2235 & 0.8999947 & insignificant
\end{tabular}

Figure 3: Results from the Turkey post-hoc test: A represents control treatment, B represents RCP scenario 2.6 treatment, $\mathrm{C}$ represents $\mathrm{RCP}$ scenario 6.0 treatment, and $\mathrm{D}$ represents $\mathrm{RCP}$ scenario 8.5 treatment.

From this data analysis, it was found that there was a modest decrease (from 10 to 20 percent) in bacterial colony numbers relative to the control for all treatments, however, the decrease was statistically significant only for the conditions representing scenarios 6.0 and 8.5. The mean number of viable bacteria colonies from the control treatment was about 82 colonies; the mean number of viable bacteria colonies from the RCP 2.6 treatment was about 74 colonies; the mean number of viable 
bacteria colonies from the RCP 6.0 treatment was about 67 colonies; the mean number of viable bacteria colonies from the RCP 8.5 treatment was about 66 colonies.

There is considerable variation among the replicates. The reason for this may be a result of human error, however, the specifics are largely unknown. One possible reason for variation is the difference in the population density of microbes within the sponge. Since each individual sponge fragment was only measured and not weighed, this could have resulted in some fragments having a larger population of microbes at the beginning of the experiment, affecting the results.

Although there was a larger proportion of viable bacteria from the control treatment when compared to the RCP treatments, this does not indicate causation. The one-way ANOVA test revealed that there were significant mathematical variations among the treatments. The specific treatments which were different were revealed by the Turkey Post-hoc test to be RCP treatments 6.0 and 8.5 when compared to the control treatment.

Although bacteria from the marine sponge, Halichondria panicea, were inoculated onto agar plates and counted for colonies, it cannot be certain that the bacteria were from the genus Rhodobacter (Proteobacteria, subdivision a). Due to limitations in equipment, the bacteria's DNA sequence was not identified and compared to pre-existing records; however, steps were taken to increase the chances of viable colonies from $R$ bodobacter (Proteobacteria, subdivision a). These steps include inoculation onto a selective gram-negative plate and filtration with 1-micron syringe filters.

\section{- Conclusion}

RCP scenarios 6.0 and 8.5 are statistically different from the control treatment according to a Tukey post-hoc test conducted on the raw data. The results suggest that if climate change continues along a 6.0 or 8.5 pathway, bacteria within marine sponges may be significantly affected. Recent research has shown that this may already be happening to certain symbiotic bacteria within corrals. As oceans are heating up, symbiotic microbes are developing temperature-induced necrosis, which threatens their ecosystems' stability. ${ }^{10}$

\section{Acknowledgements}

I would like to thank the Cabrillo Marine Aquarium for their mentorship and guidance during my research. I also express sincere gratitude to Dr. Andres Carrillo for his experience and advice during the collection and husbandry of the sponges.

\section{References}

1. Topic 2: Future changes, risks and impacts https://ar5-syr.ipcc. ch/topic_futurechanges.php (accessed Nov 10, 2020).

2. IPCC - Intergovernmental Panel on Climate Change https://www.ipcc.ch/ (accessed Nov 10, 2020).

3. Climate Change, Ocean Acidification and Sponges: Impacts across Multiple Levels of Organization, $1^{\text {st }}$ ed.; Carballo, J. L., Bell, J., Eds.; Springer International Publishing: Cham, Switzerland, 2017.

4. Amade, P.; Pesando, D.; Chevolot, L. Antimicrobial Activities of Marine Sponges from French Polynesia and Brittany.

Mar. Biol.1982, 70(3), 223-228.

5. Althoff, K.; Schütt, C.; Steffen, R.; Batel, R.; Müller, W. E. G. Evidence for a Symbiosis between Bacteria of the Genus
Rhodobacter and the Marine Sponge Halichondria Panicea : Harbor Also for Putatively Toxic Bacteria? Mar. Biol. 1998, 130 (3), 529-536.

6. Maejima, Y.; Kushimoto, K.; Muraguchi, Y.; Fukuda, K.; Miura, T.; Yamazoe, A.; Kimbara, K.; Shintani, M. Proteobacteria and Bacteroidetes Are Major Phyla of Filterable Bacteria Passing through 0.22 Mm Pore Size Membrane Filter, in Lake Sanaru, Hamamatsu, Japan. Biosci. Biotechnol. Biochem. 2018, 82 (7), 1-4.

7. Laport, M. S. Isolating Bacteria from Sponges: Why and How? Curr. Pharm. Biotechnol. 2017, 18 (15), 1224-1236.

8. Ocean Acidification Climate change and tropical sponges: The effect of elevated $\mathrm{pCO}_{2}$ and temperature on the sponge holobiont https://news-oceanacidification-icc.org/2017/ 05/16/climate-change-and-tropical-sponges-the-effectof-elevated- $\mathrm{PCO}_{2}$-and-temperature-on-the-sponge-holobiont/ (accessed Nov 10, 2020).

9. Kainth, P.; Gupta, R. S. Signature Proteins That Are Distinctive of Alpha Proteobacteria. BMC Genomics 2005, 6 (1), 94.

10.Fan, L., Liu, M., Simister, R., Webster, N., \& Thomas, T. (2013, May). Marine microbial symbiosis heats up: The phylogenetic and functional response of a sponge holobiont to thermal stress. Retrieved November 16, 2020, from https://www.ncbi.nlm.nih.gov/pmc/articles/PMC3635241/.

\section{- Author}

George Hasnah is a dedicated and passionate high school researcher. He hopes to peruse a career in microbiology and is a devoted activist in the fight against climate change. Through his passions, he has started several environmental clubs at his school and a non-profit organization, helping students in STEM. 